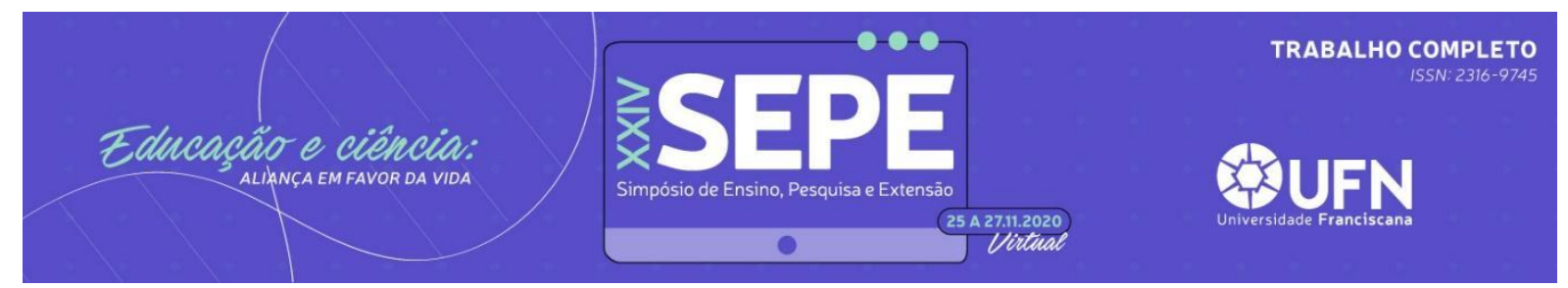

http://doi.org/10.48195/sepe2021-114

\title{
ABORDAGENS E MÉTODOS LÚDICOS PARA REMOÇÃO DA CHUPETA: UMA REVISÃO DA LITERATURA
}

\section{Anuar Said Oliveira ${ }^{1}$, Júlia Xavier Rossi ${ }^{1}$, Cândida Bonadiman Jung ${ }^{2}$, Cristiane Medianeira Savian ${ }^{3}$, Simone Pippi Antoniazzi ${ }^{4}$, Maurício Barbieri Mezomo4, Bianca Zimmerman Santos ${ }^{4}$, Letícia Westphalen Bento ${ }^{5}$}

\footnotetext{
${ }^{1}$ Acadêmico do Curso de Odontologia - Universidade Franciscana - UFN

${ }^{2}$ Mestranda em Saúde Materno Infantil - Universidade Franciscana - UFN

${ }^{3}$ Mestre em Saúde Materno Infantil - Universidade Franciscana - UFN

${ }^{4}$ Professor(a) do Curso de Odontologia - Universidade Franciscana - UFN

${ }^{5}$ Orientadora. Professora do Curso de Odontologia - Universidade Franciscana - UFN
}

\section{RESUMO}

O objetivo deste trabalho foi identificar os métodos e abordagens já descritos para a remoção da chupeta, de forma lúdica, no intuito que esse processo seja conduzido da forma mais respeitosa possível. Para isso, foi realizada uma revisão narrativa da literatura, a partir das bases de dados Pubmed/MEDLINE e Biblioteca Virtual de Saúde utilizando os seguintes descritores: "criança”, "chupeta”, "má oclusão” ou sua versão em inglês "child", "pacifiers" e "malocclusion" combinados pelo operador booleano AND. Os estudos encontrados sugerem que a estratégia mais eficaz para remoção da chupeta, tenha como base o esclarecimento aos pais ou responsáveis sobre o problema, seguido de apresentação de forma simples e clara à criança da importância da suspensão do hábito e a utilização de recursos motivacionais para auxiliar na conscientização da criança, tais como: vídeos, histórias, fantoches e 'árvores de chupeta'. 


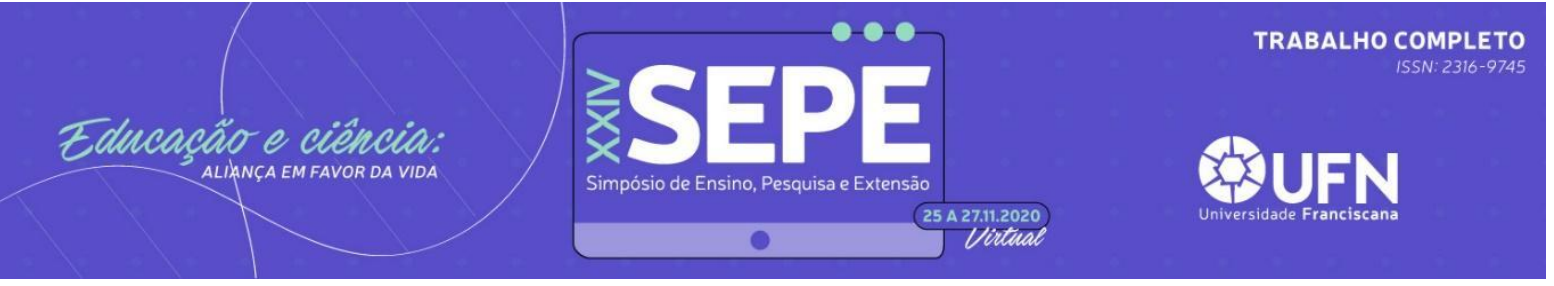

Palavras-chave: Hábitos bucais; Prevenção; Sucção não-nutritiva.

Eixo Temático: Saúde Materno Infantil (SMI).

\section{INTRODUÇÃO}

O uso da chupeta, em algumas situações, é considerado o meio mais prático para acalmar a criança, traduzindo uma conotação de tranquilidade. No entanto, quando frequentemente utilizada, pode induzir a criança a buscar um prazer fácil e vazio, pois deixa de ter outros estímulos e descobertas importantes para o seu desenvolvimento (AGUIAR et al., 2005). A chupeta também oferece apoio emocional. Dessa forma, o hábito de sucção da chupeta pode trazer consequências emocionais a criança, causando dependência do objeto, o que acaba dificultando a sua remoção (MENDES et al., 2019).

A gravidade da maloclusão depende da freqüência, intensidade e duração do hábito (SILVA, 2006). A Tríade de Graber é composta pela intensidade do hábito, ou seja a força que é realizada durante a sucção; pela frequência ou quantas vezes durante o dia ocorre a sucção; e a duração,ou seja, te em por quanto tempo a sucção é mantida (FARIAS et al., 2010).

O hábito de sucção da chupeta é considerado fisiológico até os 3 anos, se ele persistir além dessa idade ele é considerado sinal de ansiedade, instabilidade ou um desejo de atrair a atenção (AGUIAR et al., 2005). Tais sinais podem causar repercussões sobre o ambiente social e nível organizacional, podendo provocar alterações na mastigação, fala e estética, pois as pressões anormais na arcada que ocorrem com a sucção podem gerar desvios no crescimento normal das estruturas dentofacias e se tornando prejudicial a criança se não for removido (Muzulan; Gonçalves, 2011). Portanto, o objetivo deste trabalho foi identificar os métodos e abordagens lúdicas já descritos para remoção da chupeta no intuito de conduzir o processo de forma respeitosa e com a aceitação da criança. 

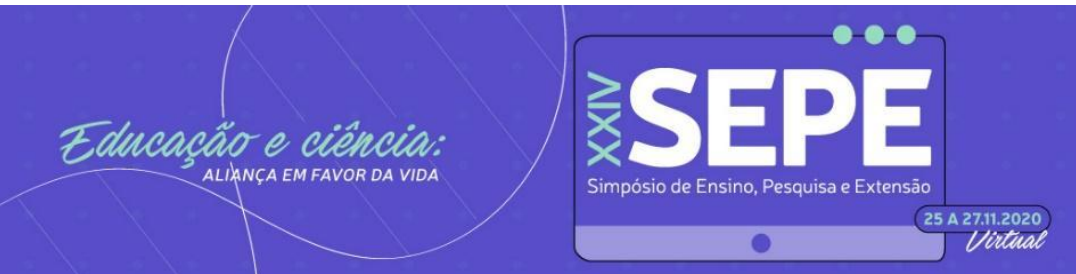

\section{OUFN}

\section{METODOLOGIA}

Para tanto, foi realizada uma revisão de literatura para seu desenvolvimento, foi executada uma busca de artigos referentes ao tema, nas bases de dados PubMed/MEDLINE e BVS (Biblioteca Virtual em Saúde). A pesquisa foi realizada no mês de julho de 2021. Foram utilizados os seguintes descritores: "criança", "chupeta", "má oclusão" ou sua versão em inglês "child", "pacifiers" e "malocclusion" combinados pelo operador booleano AND. Após essa etapa, realizou-se a leitura dos títulos e resumos de todos os artigos encontrados, para adequada inclusão dos trabalhos relacionados ao tema. As referências dos trabalhos incluídos também foram revisadas para encontrar possíveis artigos que pudessem ser incluídos. Não foi realizada a delimitação temporal visando obter todos os trabalhos já desenvolvidos sobre o assunto nas base de dados citadas.

\section{RESULTADOS E DISCUSSÃO}

No presente estudo, foram encontrados cinco artigos que contemplam a temática (AGUIAR, 2005; FARIAS, 2012; PEREIRA, 2010; MUZULAN, 2011; MENDES, 2019). Destes, três (MENDES, 2019; PEREIRA, 2010; AGUIAR, 2005) sugerem a utilização de uma técnica para remover o hábito de sucção da chupeta dividida em 4 etapas: na primeira etapa se realiza o esclarecimento aos pais ou responsáveis, através de um questionário, no qual se identifica as crianças que fazem uso de chupeta. Após, recebem orientações sobre a necessidade e a importância da remoção do hábito de sucção, e sobre hábitos de higiene bucal.

Para que os pais pudessem reconhecer as alterações e identificar a situação de seus filhos é apresentado a eles fotos clínicas de mordida aberta, mordida cruzada e de oclusão normal . Na segunda etapa é apresentado, de forma simples e clara, as orientações às crianças sobre as alterações causadas pela chupeta e os cuidados com a saúde bucal. $\mathrm{Na}$ terceira etapa são aplicados recursos motivacionais, com vídeos, histórias ilustrativas e fantoches sobre hábitos deletérios e de higiene bucal. Ao introduzir essa técnica, é contada uma história à criança que 


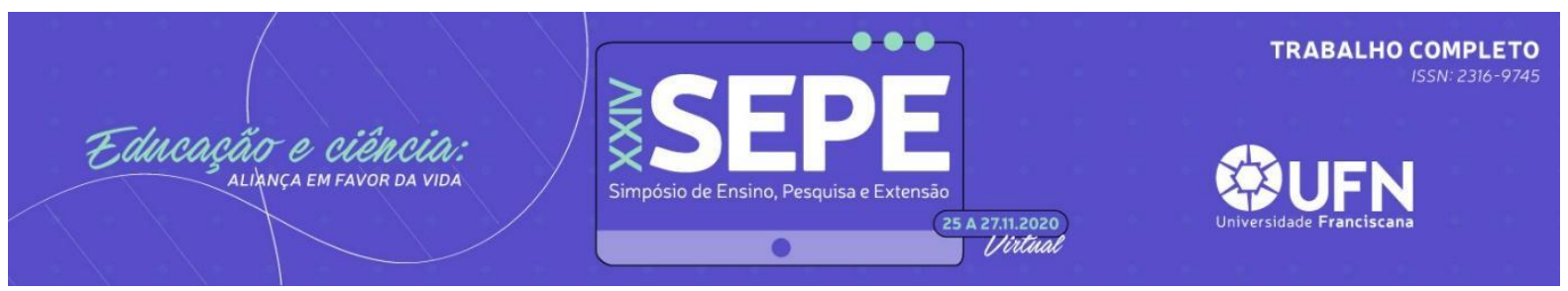

contextualiza a ação que ela praticaria posteriormente depositando a chupeta em uma árvore criada para ilustração.

A escolha do método para a remoção do hábito de sucção de chupeta deve contemplar a aceitação da criança, os aspectos emocionais possivelmente envolvidos no hábito, a colaboração da família e da escola, assim como a habilidade do educador em saúde (PEREIRA et al., 2010). Os pais tem sido orientados a não interferirem na decisão dos filhos, entretanto, deveriam estimulá-los quando apresentassem o comportamento desejado, com elogios, sorrisos ou abraços, a depender de qual atitude seria a mais reforçadora para cada criança. Contudo, observou-se que $100 \%$ dos pais concordam que a sua colaboração e seu incentivo são fundamentais para a criança abandonar o hábito (MUZULAN; GOLÇALVES, 2011). Outro estudo relata que o sucesso da técnica será maior se houver mais participação dos pais durante a primeira etapa do estudo e motivação da família e da escola para o abandono do hábito de sucção (PEREIRA et al., 2010).

Em outra pesquisa (MUZULAN; GOLÇALVES, 2011), o método foi dividido em dez sessões, realizadas uma vez na semana com duração de uma hora, ao final de cada sessão os pais recebiam orientação semanal. As primeiras teve foco na conscientização dos prejuízos causados pela sucção da chupeta, por meio de figuras, fotos e espelho, com objetivo de motivar as crianças a removerem os hábitos e esclarecer as dúvidas sobre o assunto. Na quarta sessão, foi contada uma história infantil abordando temas como mau hálito e as consequências dos hábitos orais nas funções do aparelho estomatognático. As crianças foram orientadas de que a chupeta e o dedo levam "bichinhos" e micróbios para dentro da boca, deixando-a com cheiro ruim, suja e com muitas bactérias. Na quinta sessão, já com a sensibilização da criança quanto à importância de abandonar o hábito, foram selecionadas atividades diárias que prendessem sua atenção e ajudassem a se lembrar dos prejuízos causados pelo hábito. Com a utilização de cartolinas, figuras e canetinhas, cada criança confeccionou vários lembretes e estes foram distribuídos em diferentes locais da casa. 


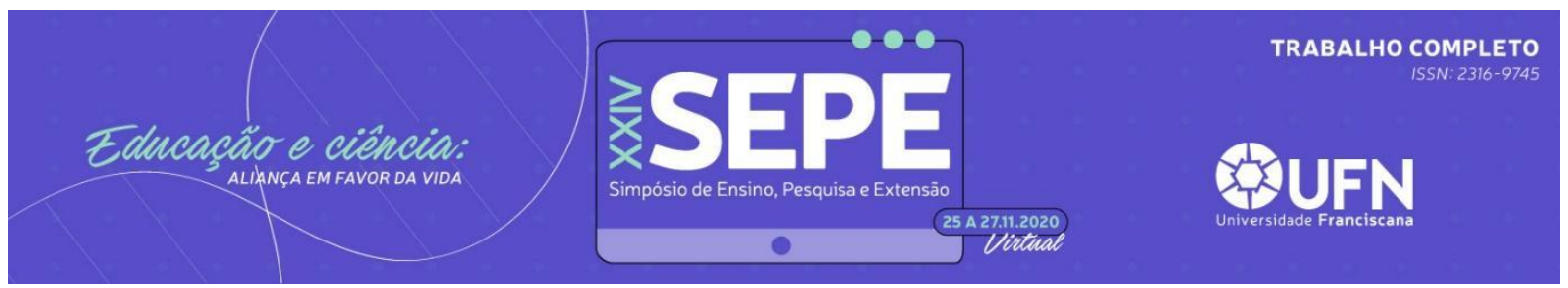

Durante a sexta sessão as crianças aprenderam uma música, de forma simplificada, para lembrar o que deveriam fazer para remover o hábito que possuíam. Na sétima sessão, cada criança confeccionou um calendário, em que os dias foram divididos em dois períodos (dia e noite). Diariamente, a criança deveria marcar com desenhos os períodos que conseguisse ficar sem o hábito. $\mathrm{Na}$ oitava sessão, foi utilizado um jogo da memória, com figuras de alterações dentárias (como mordida aberta, cruzada, profunda, apinhamentos, cáries) e figuras de arcadas corretas e dentes bonitos. A criança deveria compará-las para que fosse reforçada a importância da remoção do hábito. $\mathrm{Na}$ nona sessão, foi realizado um teatro com fantoches sobre os assuntos abordados nas sessões anteriores, relevando a importância e a necessidade da remoção dos hábitos orais. As crianças ouviram novamente a música trabalhada na sexta sessão e desenharam sobre o tema.Na décima e última sessão, houve uma confraternização com as crianças e pais. As crianças falaram sobre o que aprenderam e as que eliminaram completamente o hábito receberam certificado.

Nesse estudo todos os pais informaram que a eliminação do hábito foi mantida. O envolvimento deles foi essencial para o resultado, pois estimularam constantemente a criança em casa, motivando-a com carinho. Assim, com estímulos constantes por parte do profissional e reforços positivos em cada etapa alcançada, essas crianças conseguiram remover completamente o hábito de sucção. Os autores observaram que a necessidade de sucção pode estar ligada a fatores psicoafetivos.

$\mathrm{Na}$ perspectiva de Mendes e colaboradores (2019), o uso da estratégia motivacional é recomendado para que seja realizada além da remoção do hábito de sucção de chupeta, transmissão de conhecimentos e conscientização de crianças e adultos, para a racionalização de suas decisões quanto a utilização do objeto.

Os autores Muzulan e Gonçalves (2011) concordam quanto à necessidade da interrupção precoce, pois com ela menores serão as chances de desarmonias faciais graves, além de maior probabilidade de ocorrer auto-correção das 


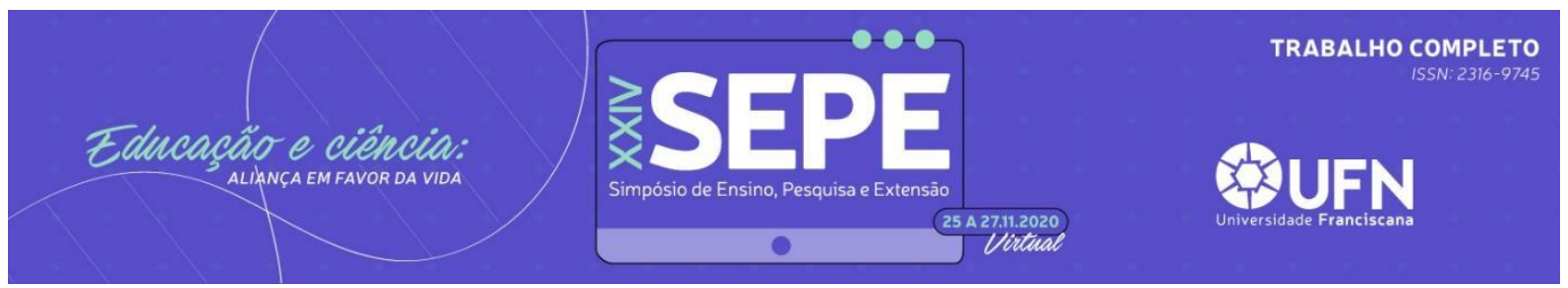

maloclusões. Contudo, não é recomendada a interrupção abrupta dos hábitos, pois se forem decorrentes de necessidades psicológicas, podem funcionar como válvula de escape de tensões e como forma de obtenção de conforto e alívio, podendo levar ao desenvolvimento de hábitos piores, tais como bruxismo e compulsão alimentar.

\section{CONCLUSÃO}

A remoção do hábito de suç̧ão de chupeta causa dúvidas nos pais relacionadas à sua abordagem e possíveis consequências psicoemocionais para a criança, além do empenho realizado pelos familiares para superar sua vinculação com o objeto como apoio para os cuidados com seus filhos. Há casos em que o abandono da chupeta causa ansiedade e irritação à criança. Anteriormente, medidas restritivas foram aplicadas no intuito de impedir que a criança mantivesse o hábito. Porém, atualmente, tem-se dado atenção para técnicas que visem o abandono por vontade própria. A aceitação da criança e a colaboração dos pais ou responsáveis é fundamental para o sucesso do tratamento, prevenindo ou minimizando as possíveis consequências. $O$ esclarecimento e a conscientização sobre as sequelas do hábito são fundamentais para a decisão de abandoná-lo. O uso de brincadeiras, histórias, fantoches e técnicas semelhantes à 'árvore da chupeta' como foi verificado nos estudos descritos, torna mais simples e com menor impacto emocional, tanto para a criança quanto para a família, o processo de deixar o hábito.

\section{REFERÊNCIAS}

AGUIAR, F. K. et al. Remoção de hábitos de sucção não nutritiva: integração da odontopediatria, psicologia e família. Arq. Odontol, v. 41, n. 4, p. 353-366, 2005. Disponível em: 


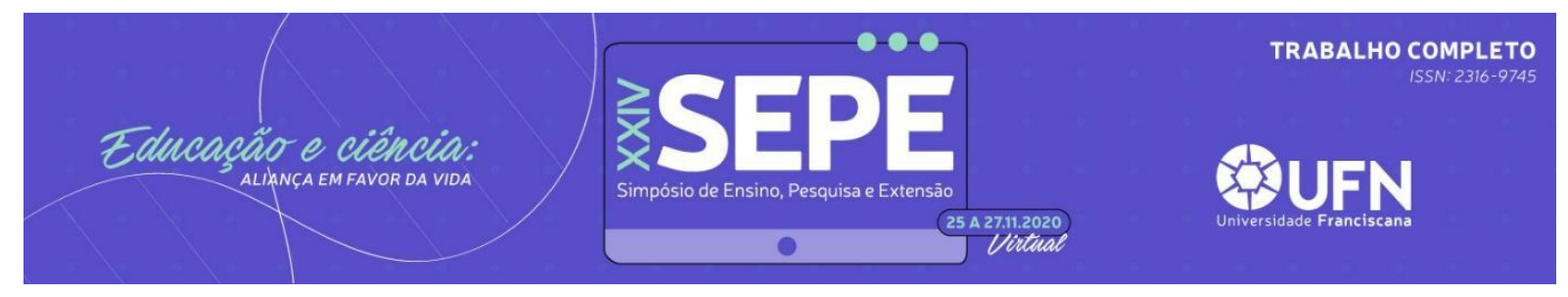

-arch8-2005.pdf

Acesso: Julho de 2021.

FARIAS, A. V. M. et al. Repercussões das estratégias de retirada dos hábitos orais deletérios de sucção nas crianças do Programa de Saúde da Família em Olinda PE. Rev. Cefac, v. 12, n. 6, p. 971-976,. 2010.

Disponível em:

https://www.scielo.br/j/rcefac/a/s8Kz63LnDdhMV6pqHsJmLGM/?format=pdf\&lang=pt Acesso em: Julho de 2021.

MENDES, M. L. M. et al. Influência da reprodução cultural sobre o hábito de sucção de chupeta. Rev. Pesq. Qual., v. 7, n. 13, p. 87-116, 2019.

Disponível em: https://editora.sepq.org.br/rpq/article/view/132/148 Acesso em: Julho de 2021.

MULAZAN, C. F; GONÇALVES M. I.R. O lúdico na remoção de hábitos de sucção de dedo e chupeta. J. Soc. Bras. Fonoaudiologo, v. 23, n. 1, p. 66-70, 2011. Disponível em: https://www.scielo.br/j/jsbf/a/zBdrPRZY3ZJqR6F8JxdCYvj/?lang=pt Acesso em: Julho de 2021.

PEREIRA, V. P. et al. Remoção do Hábito de Sucção de Chupeta em Pré-escolares: apresentação e avaliação de uma estratégia motivacional. Rev Fac Odontol PA, v. 50, n. 3, p. 57-61, 2009.

Disponível em:

https://www.seer.ufrgs.br/RevistadaFaculdadeOdontologia/article/view/12018/11667 Acesso em: Julho de 2021.

SILVA, L.S. HÁBITOS BUCAIS DELETÉRIOS. Revista Paraense de Medicina V.20 n.2, p49, abril - junho 2006. 


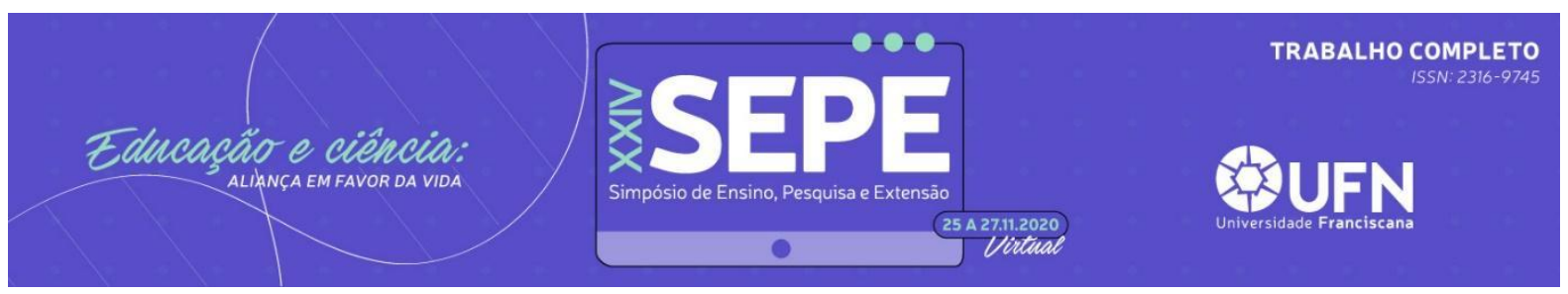

Disponível em: http://scielo.iec.gov.br/pdf/rpm/v20n2/v20n2a09.pdf

Acesso em: Julho de 2021. 